\title{
Quantum Chemical Characterization of Hydrogen Bonding Sites in Three 4-(4-Halo-Phenyl)-6-(Furan-2-yl) Pyrimidin-2-Amine Derivatives
}

\author{
Yafigui Traore, Kafoumba Bamba, Nahossé Ziao*, Sopi Thomas Affi, Mamadou Guy-Richard Kone \\ Laboratoire de Thermodynamique et de Physico-Chimie du Milieu, UFR SFA, Université NanguiAbrogoua, Abidjan, \\ Côte-d'Ivoire \\ Email: ^nahosse_ziao@yahoo.fr, ${ }^{\star}$ nahosse.ziao@una-ufrsfa.ci
}

How to cite this paper: Traore, Y., Bamba, K., Ziao, N., Affi, S.T. and Kone, M.G.-R. (2017) Quantum Chemical Characterization of Hydrogen Bonding Sites in Three 4(4-Halo-Phenyl)-6-(Furan-2-yl) Pyrimidin2-Amine Derivatives. Computational Chemistry, 5, 91-102.

https://doi.org/10.4236/cc.2017.53008

Received: May 25, 2017

Accepted: July 2, 2017

Published: July 5, 2017

Copyright $\odot 2017$ by authors and Scientific Research Publishing Inc. This work is licensed under the Creative Commons Attribution International License (CC BY 4.0).

http://creativecommons.org/licenses/by/4.0/

\begin{abstract}
Hydrogen bonding (HB) sites in three pyrimidine compounds derivatives (DP), namely 4-(4-fluorophenyl)-6-(furan-2-yl) pyrimidin-2-amine (DP-1), 4-(4-chlorophenyl)-6-(furan-2-yl) pyrimidin-2-amine (DP-2) and 4-(4-bromophenyl)6-(furan-2-yl) pyrimidin-2-amine (DP-3), have been investigated by quantum chemistry methods, especially at $\mathrm{HF} / 6-311+\mathrm{G}(\mathrm{d}, \mathrm{p})$ and B3PW91/6-311+G(d,p) levels. Hydrogenfluori deserved as probe for hydrogen bonding complexes. Molecular electrostatic potential maps, geometricparameters of $\mathrm{HB}$ complexes, as well as energetic parameters of the complexation reactions have been computed. Finally, one out of two nitrogen atoms of pyrimidine nucleus has been identified as the major hydrogen bonding site in the three pyrimidine derivatives, with respective percentages of around $83.0 \%$ and 93.2\% at $\mathrm{HF} / 6-311+\mathrm{G}(\mathrm{d}, \mathrm{p})$ and B3PW91/6-311+G(d,p) levels.
\end{abstract}

\section{Keywords}

Analgesic, Hydrogen Bonding, Pyrimidine Derivatives, Quantum Chemistry

\section{Introduction}

Pain accounts for more than $90 \%$ of medical consultations because it is present in most diseases [1] [2]. It is widely spread and has a very high social and economic cost [3]. Thus, fight against pain mobilizes medical corps, researchers and policy makers for its management [4] as well as the discovery of new molecules capable of treating it more efficiently. Pyrimidine derivatives offer a good access to new varieties as evidenced by numerous works for this purpose [5] [6]. The 
three derivatives referred to in this work belong to this group and have analgesic properties. They were synthesized by Vishal et al. [7], their 2D structures are shown in Figure 1.

Pyrimidine derivatives have many other biological properties such as antitumor and cytotoxic [8] [9], antifungal [10], anticancer [11], antibacterial [12], antimicrobial [13] [14], antioxidant, anticonvulsant [15], antituberculosis [16] and antiinflammatory activities [17]. Some compounds are even present in the basic nucleotides of DNA and RNA [18] [19]. This vast set of properties demonstrates the great interest of scientists for the derivatives of this sixmembered heterocycle. Therapeutic molecules such as pyrimidine derivatives can interact in several ways with the target proteins and one of these interactions is hydrogen bonding. Indeed, hydrogen bonding is one of the most important inter and intramolecular interactions that model the biological structures. It is defined as "an attractive interaction between an hydrogen atom of a molecule or molecular fragment D-H in which $\mathrm{D}$ is more electronegative than $\mathrm{H}$ and an atom or group of atoms of the same molecule or different molecule where there is evidence of the formation of a bond" [20]. It exists in the three classical states of matter: solid, liquid and gaseous, mainly for molecular crystals or organic liquids. Locating hydrogen bonding sites in a molecule is therefore very important. The three pyrimidine derivatives studied comprise several heteroatoms, and all of them could be hydrogen bond sites. Very little work has been devoted to the study of the competition between different potential sites of hydrogen bonding within the same molecular structure [21]. The aim of our work is to determine the preferential site of hydrogen bonding by means of quantum chemical methods, supposing that all intermolecular interactions will occur on this site. So all further synthesizing should preserve free such identified site. Otherwise, the main properties of pyrimidine would be lost. Especially, one could foresee dimerizing molecules in order to enhance analgesicproperties. Such a process must avoid hydrogen bonding site.

\section{Computational Details}

\subsection{Calculation Level}

Geometry optimization of monomers and $\mathrm{H}$-bond complexes, with hydrogen fluoride molecule as a probe, as well as the calculations of the vibration frequencies, have been carried out using Gaussian 03 software [22], in blink, at the $\mathrm{HF} / 6-311+\mathrm{G}(\mathrm{d}, \mathrm{p})$ and $\mathrm{B} 3 \mathrm{PW} 91 / 6-311+\mathrm{G}(\mathrm{d}, \mathrm{p})$ levels. Diffuse and polarization

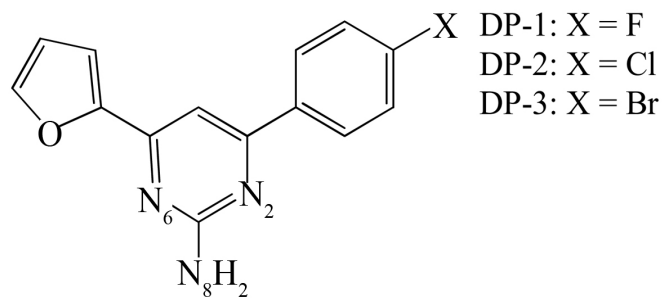

Figure 1. Structures of the pyrimidine derivatives. 
functions are important, whenever the matter is intermolecular interactions. Furthermore, taking into account basis set superposition error (BSSE) led to more quantitative results. Each of the H-bond complexes has been fully optimized, followed by frequency calculation at the same levels of theories. BSSE calculation has been madeaccordingBoys and Bernardi method [23].

\subsection{Molecular Electrostatic Potential (MEP)}

Electrostatic potential is the interaction energy between a molecule and a positive unit charge (proton) placed at a point of its environment. It is by the electrostatic potential that a molecule is first "seen" or "estimated" by another chemical species that approaches it [24]. It is a real physical property that can be determined theoretically as well as experimentally by X-ray diffraction methods [24] [25]. It is defined by the expression 1 below in atomic unit [24] [25] [26].

$$
V^{E S}(\boldsymbol{r})=\sum_{A} \frac{Z_{A}}{\left|\boldsymbol{R}_{A}-\boldsymbol{r}\right|}-\int \frac{\rho\left(\boldsymbol{r}^{\prime}\right)}{\left|\boldsymbol{r}^{\prime}-\boldsymbol{r}\right|} \mathrm{d} \boldsymbol{r}^{\prime}
$$

$Z_{A}$ is the charge of the nucleus $A$, located at $\boldsymbol{R}_{A} \mathrm{~A}$ and $\rho\left(\boldsymbol{r}^{\prime}\right)$ the electron density function of the molecule. Molecular electrostatic potential is an important tool for predicting the reactive properties of a molecule and it has been widely used, especially in the case of electrostatic reactions [24] such as hydrogen bonding interactions. Thus an electrophilic attack will tend to occur at the region where the potential $V(\boldsymbol{r})$ is the most negative [27], the local minima [24].

\subsection{Geometry Optimization}

Each of the DP derivatives has four heteroatoms. Four hydrogen bonding complexes were constructed, with the hydrogen fluoride molecule (HF) as the hydrogen bond donor (HBD). The characteristic geometric parameters of an hydrogen bond [28] are presented in Figure 2.

$\alpha$ is the HB linearity angle, $\theta$ is the directionality angle, $d$ length of Hydrogen bond. Thus, before starting a computation on a complex, the initial values below have been assigned (Figure 3): $\alpha=180^{\circ}, \theta_{1}=\theta_{2}=120^{\circ}$ for $\mathrm{sp}^{2}$ nitrogen and oxygen, $\theta_{1}=\theta_{2}=\theta_{3}=109.5^{\circ}$ for the sp $\mathrm{s}^{3}$ nitrogen and $d=2 \AA$ for all the complexes.

\subsection{Energetic Parameters}

Energetic parameters of the hydrogen bond were calculated considering the

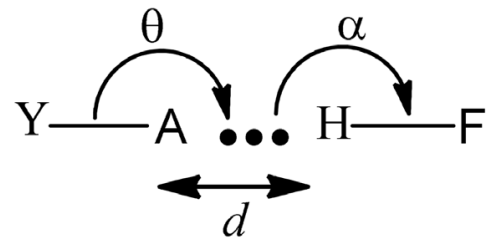

Figure 2. Geometric parameters $\alpha, \theta$ and $d$ describing an Hydrogen bond. 

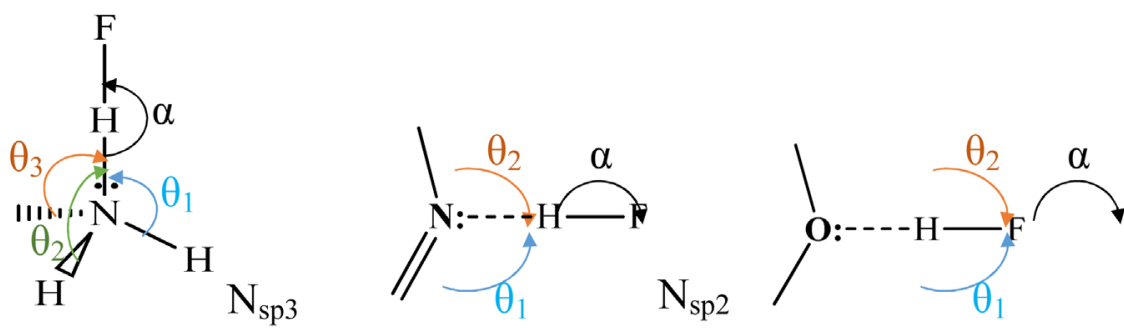

Figure 3. Definition of geometric parameters characteristic of hydrogen bond.

formation of complexes on each heteroatom according Reaction (2):

$$
\mathrm{A}+\mathrm{D} \rightarrow \mathrm{A} \cdots \mathrm{D}
$$

Hydrogen bonding energy is calculated by subtracting the energies of the isolated fragments from that of the complex [23] [29] [30] [31] according to Equation (3):

$$
\Delta E(\mathrm{~A} \cdots \mathrm{D})=E_{A D}^{a \bigcup d}(\mathrm{~A} \cdots \mathrm{D})-\left[E_{A}^{a}(\mathrm{~A})+E_{D}^{d}(\mathrm{D})\right]
$$

where $E_{A}^{a}$ is the energy of the isolated fragment $\mathrm{A}$ calculated in its atomic basis and in its geometry; $E_{D}^{d}$ that of the fragment $\mathrm{D}$ and $E_{A D}^{a \cup d}$ is the energy of the complex in its geometry and in the more extended basis aUd. The energy thus computed is tainted by the BSSE due to the superposition of the two different basis.It seems mandatory to correct the BSSE for reliable results. According the counterpoise (CP) method to correct the BSSE, proposed by Boys and Bernardi [23], the corrected energy is calculated according Equation (4):

$$
\Delta E^{\mathrm{CP}}(\mathrm{A} \cdots \mathrm{D})=\Delta E(\mathrm{~A} \cdots \mathrm{D})+\delta^{\mathrm{BSSE}}
$$

$\delta^{\text {BSSE }}$ stands for BSSE. Calculations are carried out at a temperature of 298.15 $\mathrm{K}$ under normal atmospheric pressure ( $P=1 \mathrm{~atm})$. Moreover, the total energy $E$ of an isolated molecule is obtained by summing the energies of the electronic movements, translation, rotation and vibration [32] according to Equation (5):

$$
E=E_{\text {translation }}+E_{\text {rotation }}+E_{\text {vibration }}+E_{\text {electronic }}
$$

In the perfect gas approximation, the translation and rotation contributions are given by the Relations (6), (7) and (8). For nonlinear molecule A and A ‥ D:

$$
E_{\text {translation }}=E_{\text {rotation }}=\frac{3}{2} R T
$$

For the diatomic molecule $\mathrm{D}(\mathrm{HF})$ :

$$
\begin{aligned}
E_{\text {translation }} & =\frac{3}{2} R T \\
E_{\text {rotation }} & =R T
\end{aligned}
$$

The contribution of the vibration motion to the total energy is given by Equation (9):

$$
E_{\text {vibration }}=\mathrm{ZPVE}+E_{\text {thermal }}
$$

The Zero Point Vibrational Energy (ZPVE) contribution is the lowest vibrational level energy due to the $3 N-6$ normal vibration modes $(3 N-5$ for linear 
molecules) of frequencies $v_{i}$ of the $N$ kernels at $0 \mathrm{~K}$, and defined by relation 10 :

$$
\mathrm{ZPVE}=\frac{1}{2} R \sum_{i}^{3 N-6} \frac{h v_{i}}{k}
$$

The contribution $E_{\text {thermal }}$ is the additional energy due to the population of vibration levels during the temperature rise from 0 to $T=298.15 \mathrm{~K}$, and defined by Equation (11):

$$
E_{\text {thermal }}=R \sum_{i}^{3 N-6} \frac{h v_{i} / k}{\mathrm{e}^{h v_{i} / T}-1}
$$

Finally, the change in the internal energy $E$ upon Reaction (2) to $298 \mathrm{~K}$ is given by expression 12 :

$$
\Delta E_{298}^{0}=\Delta E_{\text {elec }}+\Delta \mathrm{ZPVE}+\Delta E_{\text {therm }}-\frac{5}{2} R T
$$

Frequencies calculations provide these different electronic, vibrational and thermal contributions, as well as entropy. The enthalpy variation at $298.15 \mathrm{~K}$ is given by the expression 13 :

$$
\Delta H_{298}^{0}=\Delta E_{298}^{0}-R T
$$

Free Enthalpy variation, at $298.15 \mathrm{~K}$, is given by Equation (14):

$$
\Delta G_{298}^{0}=\Delta H_{298}^{0}-T \Delta S_{298}^{0}
$$

Variation in entropy, $\Delta S_{298}^{0}$, is calculated according to expression 15:

$$
\Delta S_{298}^{0}=S(\mathrm{~A} \cdots \mathrm{D})-S(\mathrm{~A})-S(\mathrm{D})
$$

\section{Results and Discussion}

\subsection{Molecular Electrostatic Potentials}

Molecular electrostatic potential maps of studied DP were designed after optimization at B3PW91/6-311+G(d,p). Potential surfaces (Figure 4) are associated

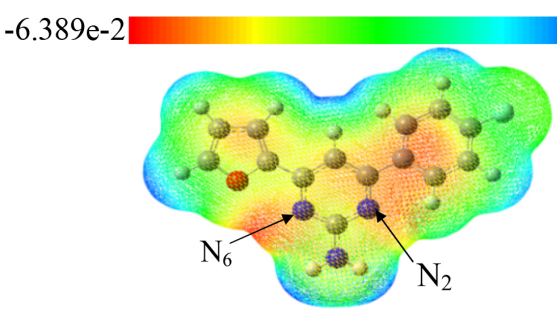

DP-1
$6.389 \mathrm{e}-2-6.788 \mathrm{e}-2$

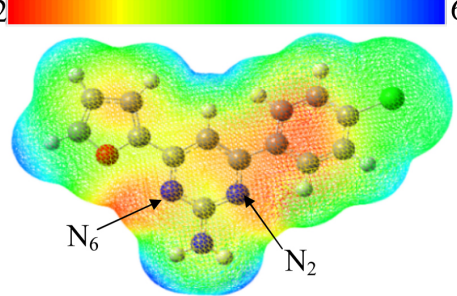

DP-2

$-7.235 e-2$ $7.235 \mathrm{e}-2$

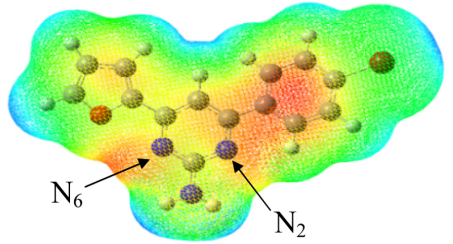

DP-3

Figure 4. Molecular electrostatic potential maps of the three pyrimidine derivatives. 
with a color code evolving continuously from red indicating the most negative potentials to blue indicating the most positive potentials [33]. These maps indicate that the heteroatom N6 is favorable to an electrophilic attack given its approaching zone which is the redder. As for the other heteroatoms, $\mathrm{O}$ and N8 are disadvantaged for electrophilic attacks because of their approach zones which are in the green whereas $\mathrm{N} 2$, whose approach zone is orange, is less favorable than N6. The results are similar for the three molecules. It is thus apparent that $\mathrm{N} 2$ and N6 nitrogen atoms of pyrimidine nucleus are the most nucleophilic, thus favorable to hydrogen bonding in these three derivatives.

\subsection{Geometric Parameters}

Geometry optimization of the hydrogen bond complexes on the oxygen atom did not succeed. Indeed, after optimization, migration of the probe from the oxygen atom to the N6 nitrogen atom of the pyrimidine nucleus is observed, whatever the DP molecule.

This phenomenon may be explained by the participation of one of the lone pairs of oxygen atom in the aromatic character of the furan. The commitment of this doublet in electronic delocalization depletes the oxygen atom. Probe migrations have recently been observed in studies conducted by Ziao et al. [34] [35], both in the case of two imidazopyridinyl-chalcone derivatives and four benzimidazolyl-chalcone derivatives using water molecule as probe. Thus, only energetic parameters of the complexes on the nitrogen atoms of these three DP molecules have been calculated. Geometric parameters of the complexes formed on the three nitrogen atoms are recorded in Table 1 below.

Results of Table 1 show that for the same level of calculation and hydrogen bonding site, values obtained for each parameter are virtually the same from one molecule to another. Thus for the linearity angles $\alpha$ of the complexes formed on the $\mathrm{N} 2$ and $\mathrm{N} 6$ atoms with $\mathrm{sp}^{2}$ hybridization, the mean values are respectively $165.7^{\circ}$ and $160.5^{\circ}$ at the DFT level and $165.3^{\circ}$ and $156.8^{\circ}$ at the HF level for the

Table 1. Geometrical parameters of hydrogen bond complexes on N2, N6 and N8 atoms.

\begin{tabular}{|c|c|c|c|c|c|c|c|c|c|c|c|c|c|}
\hline \multicolumn{14}{|c|}{$\mathrm{HF} / 6-311 \mathrm{G}(\mathrm{d}, \mathrm{p})$} \\
\hline & \multicolumn{3}{|c|}{$d$} & \multicolumn{3}{|c|}{$\alpha$} & \multicolumn{3}{|c|}{$\theta_{1}$} & \multicolumn{3}{|c|}{$\theta_{2}$} & \multirow{2}{*}{$\begin{array}{c}\theta_{3} \\
\mathrm{~N} 8\end{array}$} \\
\hline & N2 & N6 & N8 & N2 & N6 & N8 & N2 & N6 & N8 & N2 & N6 & N8 & \\
\hline DP_1 & 1.79 & 1.88 & 1.98 & 165.5 & 156.9 & 174.2 & 113.6 & 115.2 & 104.1 & 128.7 & 128.0 & 100.9 & 111.5 \\
\hline DP_2 & 1.79 & 1.88 & 1.98 & 165.2 & 156.7 & 174.3 & 113.6 & 115.2 & 104.1 & 128.8 & 127.9 & 100.9 & 111.4 \\
\hline DP_3 & 1.79 & 1.88 & 1.98 & 165.1 & 156.7 & 174.4 & 113.6 & 115.2 & 104.1 & 128.8 & 127.9 & 100.9 & 111.4 \\
\hline \multicolumn{14}{|c|}{ B3PW91/6-311G(d,p) } \\
\hline & \multicolumn{3}{|c|}{$d$} & \multicolumn{3}{|c|}{$\alpha$} & \multicolumn{3}{|c|}{$\theta_{1}$} & \multicolumn{3}{|c|}{$\theta_{2}$} & $\theta_{3}$ \\
\hline & $\mathrm{N} 2$ & N6 & N8 & $\mathrm{N} 2$ & N6 & N8 & $\mathrm{N} 2$ & N6 & N8 & N2 & N6 & N8 & N8 \\
\hline DP_1 & 1.58 & 1.64 & 1.78 & 165.8 & 160.5 & 174.9 & 111.6 & 112.1 & 103.3 & 130.8 & 131.0 & 101.6 & 112.6 \\
\hline DP_2 & 1.58 & 1.64 & 1.78 & 165.7 & 160.5 & 174.3 & 111.6 & 112.1 & 103.4 & 130.8 & 131.0 & 101.4 & 112.6 \\
\hline DP_3 & 1.58 & 1.64 & 1.78 & 165.6 & 160.4 & 174.4 & 111.6 & 112.1 & 103.5 & 130.8 & 131.0 & 101.3 & 112.6 \\
\hline
\end{tabular}


DP-1

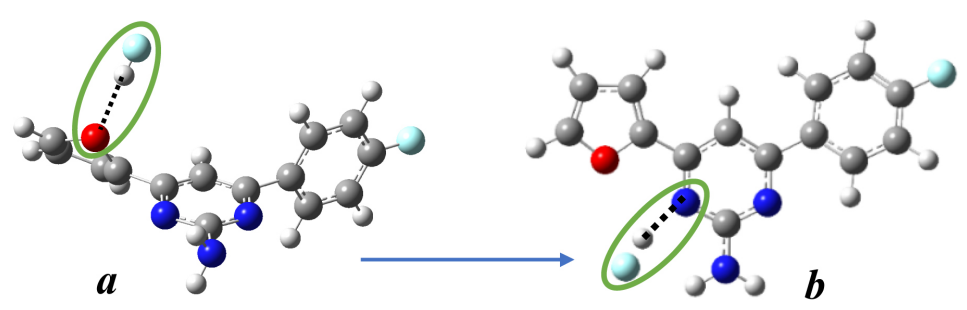

DP-2

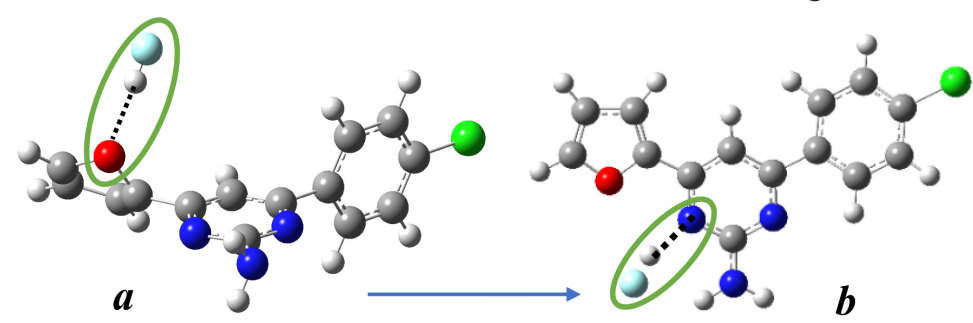

DP-3

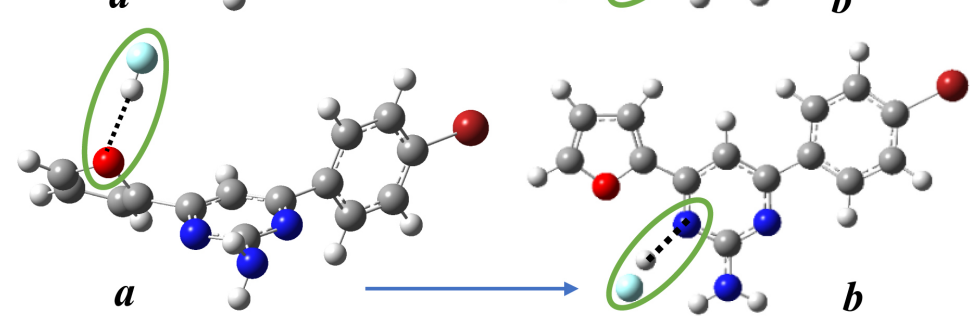

Figure 5. Geometries of hydrogen bond complexes on oxygen of furan in DP: (a) before optimization (b) after optimization.

three molecules. For the nitrogen N8 with $\mathrm{sp}^{3}$ hybridization we have $174.5^{\circ}$ and $174.3^{\circ}$. The approach direction angles for N2 and N6 are such that $\theta 1<\theta 2$ for in nearly any case. This can be explained by the fact that the fluorine atom $\mathrm{F}$ having a high electron density can be a proton acceptor and especially an acid proton of the closer basic fragment $\mathrm{N}_{8} \mathrm{H}_{2}$. And this atom can form another hydrogen bond (F … H (N8)). This type of HB has already been investigated [36] [37] [38]. This new $\mathrm{HB}$ thus reduces the approach direction angle of the N8 side. For complexes formed on $\mathrm{N} 8$, the results indicate $\theta_{1} \approx \theta_{2}<\theta_{3}$. This result can be explained by the repulsion between the electron density of the pyrimidine nucleus and that of the $\mathrm{F}$ atom of the hydrogen fluoride.The $\mathrm{sp}^{2}$ nitrogen atom has a single lone pair pointing in a direction of $120^{\circ}$ with each of the two adjacent single bonds. As for the $\mathrm{sp}^{3}$ nitrogen, the lone pairpoints out with an angle at about $109^{\circ}$ with each of the three adjacent single bonds. Given the electrostatic character of HB, it will therefore tend to form in the optimal direction of the lone pair. Moreover, the mean values of the angles of direction $\theta$, of the complexes on N2 and N6 at the DFT level are in the same order $121.2^{\circ}$ and $121.5^{\circ}\left(121.2^{\circ}\right.$ and $121.6^{\circ}$ at the HF level) and $105.8^{\circ}\left(105.5^{\circ}\right)$ for $\mathrm{N} 8$ atom. These mean values are very close to optimal values. Concerning the lengths $d$ of $\mathrm{HB}: d(\mathrm{~N} 2 \cdots \mathrm{H})=1.58 \AA ⿻$ $1.64 \AA$ and $d(\mathrm{~N} 8 \cdots \mathrm{H})=1.78 \AA$ at the DFT level and $d(\mathrm{~N} 2 \cdots \mathrm{H})=1.79 \AA$, $d(\mathrm{~N} 6 \cdots \mathrm{H})=1.88 \AA$ and $d(\mathrm{~N} 8 \cdots \mathrm{H})=1.98 \AA$ at the HF level. These values are all lower than $2.65 \AA$ sum of Van der Waals radii of nitrogen atom with $1.55 \AA$ and hydrogen atom with $1.1 \AA$ [39]. This result thus provides H-link contacts. Finally, the analysis of the set of geometric parameters indicated the possible formation of intermolecular hydrogen bond on nitrogen atoms in these three 
pyrimidine derivatives.

\subsection{Energetic Parameters}

All values of the enthalpies changes are negative (Table 2), expressing exothermic reactions whereas some values of the free enthalpies changes are negative translating spontaneous complexations, while others are positive, showing nonspontaneous reactions in the conditions of the study. Thus, the two levels of theory predict spontaneous reactions on N6 for the three derivatives and on N2 for the DP-1 and DP-2 derivatives; for DP-3, the HF method predicts a spontaneous reaction and DFT provides a non-spontaneous reaction as on nitrogen $\mathrm{N} 8$ for the two theories levels. A classification in ascending order of the free enthalpy change of complexation gives the following result for each derivative, and also for each computation level:

$\Delta G_{298}^{0}(\mathrm{~N} 6 \cdots \mathrm{HF})<\Delta G_{298}^{0}(\mathrm{~N} 2 \cdots \mathrm{HF})<\Delta G_{298}^{0}(\mathrm{~N} 8 \cdots \mathrm{HF})$. It appears from this energetic study that on N6 nitrogen atom, the variation of the free enthalpy of complexation is the smallest, values being $-4.649 \mathrm{kcal} / \mathrm{mol},-4.500 \mathrm{kcal} / \mathrm{mol}$ and $-0.951 \mathrm{kcal} / \mathrm{mol}$ with DFT method and $-1.840 \mathrm{kcal} / \mathrm{mol},-1.758 \mathrm{kcal} / \mathrm{mol}$ and $-1.740 \mathrm{kcal} / \mathrm{mol}$ with HF method respectively for DP-1, DP-2 and DP-3. Therefore N6 is the preferred hydrogen bonding site in these pyrimidine derivatives.

However, the relatively small differences between changes in free enthalpy of complexation at the $\mathrm{N} 2$ and N6 atoms ranging from $0.745 \mathrm{kcal} / \mathrm{mol}$ to 1.159 $\mathrm{kcal} / \mathrm{mol}$ at the DFT level and $1.530 \mathrm{kcal} / \mathrm{mol}$ to $1.585 \mathrm{kcal} / \mathrm{mol}$ at the $\mathrm{HF}$ level could justify the existence of competition between these sites. It is therefore necessary to calculate the relative abundances of the complexes formed on the N2 and N6 sites. To do this, we will analyze the complexation equilibria on the nitrogen atoms N2 and N6.

Table 2. Energetic parameters of hydrogen bonding reactions. $\left(\Delta H_{298}^{0}, \Delta G_{298}^{0}\right.$ in $\mathrm{kcal} / \mathrm{mol}$ and $\Delta S_{298}^{0}$ in $\left.\mathrm{cal} / \mathrm{mol} \cdot \mathrm{K}\right)$.

\begin{tabular}{|c|c|c|c|c|c|c|c|c|c|}
\hline & \multicolumn{9}{|c|}{$\mathrm{HF} / 6-311+\mathrm{G}(\mathrm{d}, \mathrm{p})$} \\
\hline & \multicolumn{3}{|c|}{$\mathrm{N} 2 \cdots \mathrm{HF}$} & \multicolumn{3}{|c|}{ N6 $\cdots H F$} & \multicolumn{3}{|c|}{ N8 $\cdots H F$} \\
\hline & $\Delta H_{298}^{0}$ & $\Delta S_{298}^{0}$ & $\Delta G_{298}^{0}$ & $\Delta H_{298}^{0}$ & $\Delta S_{298}^{0}$ & $\Delta G_{298}^{0}$ & $\Delta H_{298}^{0}$ & $\Delta S_{298}^{0}$ & $\Delta G_{298}^{0}$ \\
\hline DP_1 & -9.018 & -29.389 & -0.256 & -10.472 & -28.951 & -1.840 & -5.521 & -26.276 & 2.314 \\
\hline DP_2 & -8.956 & -29.275 & -0.227 & -10.384 & -28.932 & -1.758 & -5.432 & -26.256 & 2.396 \\
\hline \multirow[t]{4}{*}{ DP_3 } & -8.910 & -29.201 & -0.203 & -10.361 & -28.915 & -1.740 & -5.410 & -26.265 & 2.421 \\
\hline & \multicolumn{9}{|c|}{ B3PW91/6-311+G(d,p) } \\
\hline & \multicolumn{3}{|c|}{$\mathrm{N} 2 \cdots \mathrm{HF}$} & \multicolumn{3}{|c|}{ N6 $\cdots H F$} & \multicolumn{3}{|c|}{ N8 $\cdots H F$} \\
\hline & $\Delta H_{298}^{0}$ & $\Delta S_{298}^{0}$ & $\Delta G_{298}^{0}$ & $\Delta H_{298}^{0}$ & $\Delta S_{298}^{0}$ & $\Delta G_{298}^{0}$ & $\Delta H_{298}^{0}$ & $\Delta S_{298}^{0}$ & $\Delta G_{298}^{0}$ \\
\hline DP_1 & -12.847 & -30.714 & -3.689 & -13.463 & -29.563 & -4.649 & -6.987 & -27.234 & 1.133 \\
\hline DP_2 & -12.745 & -30.154 & -3.755 & -13.389 & -29.816 & -4.500 & -6.893 & -27.678 & 1.359 \\
\hline DP_3 & -12.681 & -43.230 & 0.208 & -13.334 & -41.535 & -0.951 & -6.878 & -39.624 & 4.936 \\
\hline
\end{tabular}


Table 3. Percentages of N2 and N6 nitrogen H-bond complexes.

\begin{tabular}{ccccc}
\hline & \multicolumn{2}{c}{$\mathrm{HF} / 6-311+\mathrm{G}(\mathrm{d} . \mathrm{p})$} & \multicolumn{2}{c}{ B3PW91/6-311+G(d.p) } \\
\cline { 2 - 5 } & $x_{\mathrm{N} 2}(\%)$ & $x_{\mathrm{N} 6}(\%)$ & $x_{\mathrm{N} 2}(\%)$ & $X_{\mathrm{N} 6}(\%)$ \\
\hline DP-1 & 6.44 & 93.56 & 16.52 & 83.48 \\
DP-2 & 7.02 & 92.98 & 22.15 & 77.85 \\
DP-3 & 6.95 & 93.05 & 12.39 & 87.61 \\
\hline
\end{tabular}

$$
\begin{gathered}
\mathrm{DP}+\mathrm{HF} \rightleftarrows \mathrm{N} 2 \cdots \mathrm{HF} ; \quad K_{2}=\frac{[\mathrm{N} 2 \cdots \mathrm{HF}]}{[\mathrm{DP}]} \\
\text { and } \mathrm{DP}+\mathrm{HF} \rightleftarrows \mathrm{N} 6 \cdots \mathrm{HF} ; \quad K_{6}=\frac{[\mathrm{N} 6 \cdots \mathrm{HF}]}{[\mathrm{DP}]}
\end{gathered}
$$

If we consider $x_{\mathrm{N} 2}$ and $x_{\mathrm{N} 6}$ the fractions of the complexes formed on N2 and N6 respectively, then:

$$
x_{\mathrm{N} 2}=\frac{1}{\left[1+\left(\frac{K_{6}}{K_{2}}\right)\right]} \text { and } x_{\mathrm{N} 6}=1-x_{\mathrm{N} 2} \text { with } K=\exp \left(-\frac{\Delta G_{298}^{0}}{R T}\right)
$$

The various values of $x_{\mathrm{N} 2}$ and $x_{\mathrm{N} 6}$ are summarized in Table 3.

Values in Table 3 show that, whatever the calculation method is, the complexes formed on $\mathrm{N} 2$ nitrogen are in a minority compared to those formed on N6 nitrogen. This result indicates that the N6 nitrogen atom in the pyrimidine is the major hydrogen bonding site with the average percentages of $82.98 \%$ at the B3PW91/6-311+G(d,p) level and 93.19\% at the HF/6-311+G(d,p) level.

\section{Conclusion}

$\mathrm{Ab}$ initio and DFT calculation methods have been used to determine hydrogen bonding sites of three pyrimidine derivatives usingB3PW91/6-311+G(d,p) and $\mathrm{HF} / 6-311+\mathrm{G}(\mathrm{d}, \mathrm{p})$ levels. Molecular electrostatic potentials maps, geometric and energetic parameters of hydrogen bond complexes with hydrogen fluoride as probe, were the investigation criteria. Results showed on the first hand that the nitrogen atoms $\mathrm{N} 2$ and $\mathrm{N} 6$ of pyrimidine nucleus are the most favorable to an electrophilic attack according to molecular electrostatic potentials maps. On the other hand, the geometric parameters indicated the possible formation of hydrogen bond on these heteroatoms. Finally, analysis of energetic parameters showed that nitrogen $\mathrm{N} 6$ is the major site of hydrogen bond with the percentages of $82.98 \%$ at the B3PW91/6-311+G(d,p) level and $93.19 \%$ at the HF/6$311+\mathrm{G}(\mathrm{d}, \mathrm{p})$ level. Nitrogen N2 and N6 are in the same molecular environment in the pyrimidine nucleus. Although, one can notice that N6 is far away the major hydrogen bonding site. This result confirms the absolute necessity of more investigation in order to undoubtedly determine the intermolecular interaction site in pyrimidine derivatives. So, during all further synthesizing processes, one must avoid involving nitrogen atoms N2 and N6 of pyrimidine nucleus, in order to preserve analgesic properties of pyrimidine derivatives. 


\section{References}

[1] Le Bars, D. and Willer, J.-C. (2004) EMC-Anesthésie Réanimation. Physiologie de la douleur, 1, 227-266.

[2] Jitendra, K.G., Pramod, K.S., Rupesh, D., Sambhu, C.M., Anshu, C. and Prabhakar, K.V. (2011) Synthesis and Analgesic Activity of Novel Pyrimidine Derivatives of Coumarin Moiety. Acta Poloniae Pharmaceutica - Drug Research, 68, 785-793.

[3] Harald, B., Beverly, C., Vittorio, V., Rob, C. and Derek, G. (2006) Survey of Chronic Pain in Europe: Prevalence, Impact on Daily Life, and Treatment. European Journal of Pain, 10, 287-333. https://doi.org/10.1016/j.ejpain.2005.06.009

[4] Clément Cousin (2012) Du droit du patient de recevoir des soins antalgiques à l'obligation du médecin de prendre en charge la douleur. Médecine \& Droit, 2012, 158-160. https://doi.org/10.1016/j.meddro.2012.05.001

[5] Anshu, C., Pramod, K.S., Prabhakar, V. and Rupesh, D. (2011) Synthesis of Novel Pyrimidine Derivative and Its Biological Evaluation. Analele Universitătii din Bucuresti-Chimie (serie nouă), 20, 123-140.

[6] Mohamed, M.S., Awad, S.M. and Sayed, A.I. (2010) Synthesis of Certain Pyrimidine Derivatives as Antimicrobial Agents and Anti-Inflammatory Agents. Molecules, 15, 1882-1890. https://doi.org/10.3390/molecules15031882

[7] Vishal, D.J., Kshirsagar, M.D. and Singhal, S. (2012) Synthesis and Pharmacological Study of Some Novel Pyrimidines. Der Pharmacia Sinica, 3, 343-348.

[8] Naik, T.A. and Chikhalia, K.H. (2007) Studies on Synthesis of Pyrimidine Derivatives and Their Pharmacological Evaluation. E-Journal of Chemistry, 4, 60-66. https://doi.org/10.1155/2007/507590

[9] Salman, A., Tamara, A., Naji, S. and Farooq, I.M. (2013) Synthesis, Characterization and Cytotoxic Activity of Some Pyrimidine Derivatives. Journal of Al-Nahrain University, 16, 84-92.

[10] Sun, L., Wu, J., Zhang, L.Z., Luo, M. and Sun, D.Q. (2011) Synthesis and Antifungal Activities of Some Novel Pyrimidine Derivatives. Molecules, 16, 5618-5628. https://doi.org/10.3390/molecules16075618

[11] Asmaa, E., Ehab, K. and Gedawy, M. (2013) Synthesis and Anticancer Activity of Novel 2-Pyridyl Hexahyrocyclooctathieno [2,3-d]Pyrimidine Derivatives. European Journal of Medicinal Chemistry, 63, 224-230.

[12] Bansal, S., Chaudhary, A.N. and Kothiyal, P. (2013) Microwave Assisted Synthesis and Antibacterial Activity of Pyrimidine Derivatives. International Journal of Pharmacy and Pharmaceutical Sciences, 5, 346-348.

[13] Sharma, O.P., Rajeev, K.S., Birendra, S., Varadaraj, B.G., Gautham, G.S., Jayashree, B.S. and Sreenivasan, K.K. (2012) Synthesis, Spectral Characterization \& Antimicrobial Evaluation of Some Novel Pyrimidine-2,4(1H,3H)-Diones. Indo Global Journal of Pharmaceutical Sciences, 2, 70-75.

[14] Bhargava, S. and Rajwanshi, L.K. (2013) Synthesis of Some Novel Pyrido[2,3-d]Pyrimidine Derivatives and Their Antimicrobial Investigations. Indian Journal of Chémistry, 52B, 448-452.

[15] Sonia, D., Arikkatt, B., Mathew, V., Chandran, J., Joseph, M., Bhat, A.R. and Krishnakumar, K. (2014) Highly-Efficient Conversion of Primary Amides to Nitriles Using Indium(III) Triflate as the Catalyst. International Journal of Organic and Bioorganic Chemistry, 4, 1-5. https://doi.org/10.4236/ijoc.2014.41001

[16] Madhu, R., Mahetaa, N.M., Pashab, T.Y. and Patel, S. (2013) Synthesis and Antitubercular Activity of Some Novel \{1[(1phenylethylidene) Amino] Naphtho [2,1-B] 
Furan-2-yl 4-Substituted Pyrimidin-2-Amine Derivatives. International Journal of Pharmaceutical Sciences Review and Research, 23, 72-76.

[17] Chaydhary, A., Singh, A., Kumarverma, P. and Walailak, J. (2016) Novel Series of Pyrimidine Derivatives as Anti-inflammatory Agents. Science \& Technology, 13, 789-802.

[18] Dansena, H., Hj, D. and Chandrakar, K. (2015) Pharmacological Potentials of Pyrimidine Derivative: A Review. Asian Journal of Pharmaceutical and Clinical Research, 8, 171-177.

[19] Sharma, V., Chitranshi, N. and Agarwal, A.K. (2014) Significance and Biological Importance of Pyrimidine in the Microbial World. International Journal of Medicinal Chemistry, 2014, 1-31.

[20] Arunan, E., Desiraju, G.R., Klein, R.A., Sadlej, J., Scheiner, S., Alkorta I., Clary, D.C., Crabtree, R.H., Dannenberg,J.J., Hobza, P., Kjaergaard, H.G., Legon, A.C., Mennucci, B. and Nesbitt, D.J. (2011) Definition of the Hydrogen Bond. Pure and Applied Chemistry, 83, 1637-1641. https://doi.org/10.1351/PAC-REC-10-01-02

[21] Ziao, N., Questel, J.Y.L. and N'guessan, T. (2005) Caractérisation Energétique Des Sites De Fixation De Liaisons Hydrogène Dans Les Aminonitriles Par La Méthode De La Fonctionnelle De La Densité. Journal de la Société Ouest-Africaine de Chimie, 020, 101-118.

[22] Gaussian 03, Revision C.01, Frisch, M.J., Trucks, G.W., Schlegel, H.B., Scuseria, G.E., Robb, M.A., Cheeseman, J.R., Montgomery, J.J.A., Vreven, T., Kudin, K.N., Burant, J.C., Millam, J.M., Iyengar, S.S., Tomasi, J., Barone, V., Mennucci, B., Cossi, M., Scalmani, G., Rega, N., Petersson, G.A., Nakatsuji, H., Hada, M., Ehara, M., Toyota, K., Fukuda, R., Hasegawa, J., Ishida, M., Nakajima, T., Honda, Y., Kitao, O., Nakai, H., Klene, M., Li, X., Knox, J.E., Hratchian, H.P., Cross, J.B., Adamo, C., Jaramillo, J., Gomperts, R., Stratmann, R.E., Yazyev, O., Austin, A.J., Cammi, R., Pomelli, C., Ochterski, J.W., Ayala, P.Y., Morokuma, K.,Voth, G.A., Salvador, P., Dannenberg, J.J., Zakrzewski, V.G., Dapprich, S., Daniels, A.D., Strain, M.C., Farkas, O., Malick, D.K., Rabuck, A.D., Raghavachari, K., Foresman, J.B., Ortiz, J.V., Cui, Q., Baboul, A.G., Clifford, S., Cioslowski, J., Stefanov, B.B., Liu, G., Liashenko, A., Piskorz, P., Komaromi, I., Martin, R.L., Fox, D.J., Keith, T., Al-Laham, M.A., Peng, C.Y., Nanayakkara, A., Challacombe, M., Gill, P.M.W., Johnson, B., Chen, W., Wong, M.W., Gonzalez, C. and Pople, J.A. (2004) Gaussian Incorporation, Wallingford.

[23] Daza, M.C., Dobado, J.A. and Molinaa, J.M. (1999) Basis Set Superposition Error-Counterpoise corrected Potential Energy Surfaces. Application to Hydrogen Peroxide $\cdots \mathrm{X}(\mathrm{X}=\mathrm{F}-, \mathrm{Cl}-,(\mathrm{X}=\mathrm{F}-, \mathrm{Cl}-, \mathrm{Br}-, \mathrm{Li}+, \mathrm{Na}+) \mathrm{Br}-, \mathrm{Li}+, \mathrm{Na}+)$ Complexes. Journal of Chemical Physics, 110, 11806-11813. https://doi.org/10.1063/1.479166

[24] Murray, J.S., Seminario, J.M., Concha, M.C. and Politzer, P. (1992) An Analysis of Molecular Electrostatic Potentials Obtained by a Local Density Functional Approach. International Journal of Quantum Chemistry, 44, 113-122. https://doi.org/10.1002/qua.560440204

[25] Riley, K.E., Tran, K.A., Lane, P., Murray, J.S. and Politzer, P. (2016) Comparative Analysis of Electrostatic Potential Maxima and Minima on Molecular Surfaces, as Determined by Three Methods and a Variety of Basis Sets. Journal of Scientific Computing, 17, 273-284. https://doi.org/10.1016/j.jocs.2016.03.010

[26] Drissi, M., Benhalima, N., Megrouss, Y., Rachida, R., Abdelkader, C. and Hamzaoui, F. (2015) Theoretical and Experimental Electrostatic Potential around the M-Nitrophenol Molecule. Molecules, 20, 4042-4054. https://doi.org/10.3390/molecules20034042 
[27] Balachandran, V. and Karunakaran, V. (2014) Molecular Structure, Vibrational Spectroscopic, Hyperpolarizability, Natural Bond Orbital Analysis, Frontier Molecular Orbital Analysis and Thermodynamic Properties of 2, 3, 4, 5, 6-Pentafluorophenylacetic Acid. Spectrochimica Acta Part A, 127, 473-483. https://doi.org/10.1016/j.saa.2014.02.129

[28] Desiraju, G.R. and Steiner, T. (1999) The Weak Hydrogen Bond in Structural Chemistry and Biology. Oxford University Press, Chichester.

[29] Richard, R.M., Lao, K.U. and Herbert, J.M. (2013) Achieving the CCSD (T) BasisSet Limit in Sizable molecular Clusters: Counterpoises Corrections for the ManyBady Expansion. The Journal of Physical Chemistry, 4, 2674-2680.

[30] Halkier, A., Klopper, W., Helgaker, T., Jorgensen, P. and Taylor, P.R. (1999) Basis Set Convergence of the Interaction Energy of Hydrogen-Bonded Complexes. Journal of Chemical Physics, 111, 9157-9167. https://doi.org/10.1063/1.479830

[31] Frans, B., Duijneveldt, V., Jeanne, G.C.M., Rijdt, D. and Lenth, J.H. (1994) State of the Art in Counterpoise Theory. Chemical Reviews, 94, 1873-1885. https://doi.org/10.1021/cr00031a007

[32] Ochterski, J.W. (2016) Thermochemistry. Gaussian Incorporation, Wallingford.

[33] Abdel, B.H.M., Hanan, G.E., Mohamed, M.E.O. and Ibrahim, M.A. (2015) Molecular Electrostatic Potential Analysis of Nano-Scale Fullerene (C60) Crystals and Some Specifc Derivatives: DFT Approach. Journal of Nanomaterials \& Molecular Nanotechnology, 4, 2.

[34] Affi, S.T., Nahossé, Z., Mahama, O., Drissa, S. and Kicho, Y. (2014) Caractérisation Théorique des Sites D'interaction par Liaison Hydrogène de 3-(4-Isopropylphenyl)1-(2-ethylimidazopyridin-3-yl) Prop-2-en-1-One et de 3-(2-Methoxyphenyl)-1(2-Methylimidazopyridin-3-yl) Prop-2-en-1-One. European Journal of Scientific Research, 123, 340-347.

[35] Kone M.G.R., Affi, S.T., Nahossé, Z., Kafoumba, B. and Assanvo, E.F. (2015) Hydrogenbonding Sites in Benzimidazolyl-Chalconesmolecules: An Ab Initio and DFT Investigation. Journal of Chemical and Pharmaceutical Research, 7, 805-8012.

[36] Bagheri, S., Masoodi, H.R. and Yousofvand, A. (2016) Exploring the Role of Substituents on Cooperativity between $\mathrm{N} \cdots \mathrm{HF}$ and $\mathrm{CH} \cdots \mathrm{F}$ Hydrogen Bonds in Ternary Systems Involving Aromatic Azine: Substituted Complexes of S-Triazine: HF: S-Triazine as a Working Model. Computational and Theoretical Chemistry, 1092, 12-18. https://doi.org/10.1016/j.comptc.2016.07.002

[37] Silva, D.S. and Oliveira, B.G. (2017) New Insights about the Hydrogen Bonds Formed between Acetylene and Hydrogen Fluoride: $\pi \cdots \mathrm{H}, \mathrm{C} \cdots \mathrm{H}$ and $\mathrm{F} \cdots \mathrm{H}$. Spectrochimica Acta Part A: Molecular and Biomolecular Spectroscopy, 173, 160 169. https://doi.org/10.1016/j.saa.2016.08.054

[38] Nathalia, B., Lima, D., Victor, H., Rusu, M. and Ramos, N. (2011) Hydrogen Bonds between Phthalimide and Hydrogen Fluoride: A Theoretical Study. International Journal of Quantum Chemistry, 111, 1387-1394. https://doi.org/10.1002/qua.22648

[39] Batsanov, S.S. (2001) Van der Waals Radii of Elements. Inorganic Materials, 37, 871-885. https://doi.org/10.1023/A:1011625728803 
Submit or recommend next manuscript to SCIRP and we will provide best service for you:

Accepting pre-submission inquiries through Email, Facebook, LinkedIn, Twitter, etc. A wide selection of journals (inclusive of 9 subjects, more than 200 journals)

Providing 24-hour high-quality service

User-friendly online submission system

Fair and swift peer-review system

Efficient typesetting and proofreading procedure

Display of the result of downloads and visits, as well as the number of cited articles Maximum dissemination of your research work

Submit your manuscript at: http://papersubmission.scirp.org/

Or contact cc@scirp.org 